DR WILLIAM C CRANWELL (Orcid ID : 0000-0001-6368-5738)

Article type : Research Letter

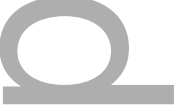

Sunscreen and facial skin care products in frontal fibrosing alopecia: a case control study<smiles>[CH]1CC1</smiles>

W.C. Cranwell ${ }^{1}$, R. Sinclair ${ }^{1,2,3}$

1. Sinclair Dermatology, Victoria, Australia

2. Department of Medicine, University of Melbourne, Victoria, Australia

3. Epworth Dermatology, Victoria, Australia

Corresponding author: Dr William C Cranwell, MBBS(Hons) BMedSc(Hons) MPH\&TM

Email:wcranwell@gmail.com

\title{
Funding:
}

No funding sources supported this work

\section{Conflict of interest disclosure:}

None to report

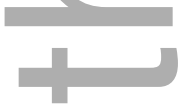

Since Kossard first described frontal fibrosing alopecia (FFA) in 1994, the incidence has increased worldwide (1). The pathophysiology remains unclear. Reports of familial FFA suggest a genetic component. Other investigators suggest hormonal, autoimmune and inflammatory processes. The epidemiology of the condition strongly implicates environmental factors. Aldoori et al reported a possible

This is the author manuscript accepted for publication and has undergone full peer review but has not been through the copyediting, typesetting, pagination and proofreading process, which may lead to differences between this version and the Version of Record. Please cite this article as doi: 10.1111/bjd.17354

This article is protected by copyright. All rights reserved 
association between FFA and leave-on facial skin care products and sunscreen (2). This was substantiated in other studies, including a questionnaire study of men with FFA $(3,4)$, and a case of regrowth following cessation of sunscreen on the forehead (5). Previous studies have not investigated the frequency of sunscreen use and the development of FFA. We aimed to further investigate the association between the use and frequency of sunscreen and facial skin-care products and FFA.

We conducted a case-control questionnaire study comparing the exposure to sunscreens, moisturisers and cosmetics between subjects with FFA and controls with any grade of female androgenetic alopecia. Patients were recruited in 2017 from a single specialist hair clinic in Melbourne, Australia. The diagnosis of FFA and androgenetic alopecia was made by a consultant dermatologist with specialist experience in hair disease. Controls were age- and sex-matched women attending the same hair clinic for androgenetic alopecia. All participants were unrelated.

Each participant completed a questionnaire about exposure to sunscreen, moisturisers, or cosmetics on the face. Cosmetics were defined as any other nonsunscreen containing compound applied to the face for cleansing, beautifying or altering the appearance. The questionnaire enquired about specific products used. Frequency of use was categorised into three groups: "Sunscreen use daily all-year", "Sunscreen use daily in summer", "Sunscreen use as needed". Demographics were reported using descriptive statistics. Comparisons between case and control groups were analysed using Fisher's exact test. To protect from Type I error, a Bonferroni correction was conducted, with a P-value of $\mathrm{P} \leq 0.017\left(\alpha_{\text {corrected }}=0.050 / 3\right)$. A chisquared test was used to assess frequency of sunscreen use. Statistical analyses were performed using Stata version 14 (StataCorp LP, College Station, Texas, U.S.A.).

We recruited 130 subjects with FFA and 130 controls. All participants were women. FFA and control subjects were well matched with regards to age (median (interquartile range): FFA 62.0 (55.0 - 68.0), androgenetic alopecia 58.0 (53.0 63.0)). 
Table 1 outlines the use of sunscreen, moisturisers and cosmetics in the case and control groups. Regular use of each product was defined as a frequency of at least twice-weekly for at least five years (as previously defined by Aldoori (2)). The use of a dedicated sunscreen in the FFA group was significant more than controls controls, with $92 \%$ of women with FFA reporting regular use $(P<0.0001)$. There was no statistical difference between the use of moisturisers between the groups. Cosmetics were used more commonly by subjects with FFA (33\%) than women with controls $(P=0.002)$.

Subjects with FFA reported more frequent use of sunscreen-containing products, with $88 \%$ reporting daily use year-round, compared with $29 \%$ in controls. The chisquared test was 96.64 with an associated $p<0.001$, meaning that frequency of sunscreen use was associated with FFA in this cohort.

The use of dedicated sunscreens, cosmeceuticals and leave-on products has greatly increased in recent decades, particularly in women (6).This trend parallels the rising incidence of FFA worldwide. In past studies, it has been difficult to assess whether products used by subjects contained sunscreen.

There are a number of hypotheses for the pathogenic role of sunscreen in FFA. One hypothesis, is that sunscreen enters the follicular infundibulum and incites a lichenoid reaction against the vellus and epidermal antigens $(3,4)$. The preponderance of FFA in postmenopausal women may be partly explained by reduced sebum production in older women, with retention of pathogenic chemicals in the follicular infundibulum (2). We hypothesise ceasing sunscreen use on the affected areas may increase ultraviolet exposure, with anti-inflammatory and immunomodulatory effects (5).

The main limitation of this study is recall bias, for the specific products and frequency of use. As was the case in previous studies, we were unable to assess ingredients, as most participants reported a brand name, rather than a specific 
product. A rigorous approach to identifying specific sunscreen-containing products is needed to assess ingredient lists.

The high frequency of sunscreen use among women with FFA supports the hypothesis that sunscreen use on the forehead may be involved in the aetiology of FFA. Extended patch testing will improve the understanding of the role of sunscreen and skin care products in the pathophysiology of FFA.

\section{References:}

1. Kossard S. Postmenopausal frontal fibrosing alopecia: scarring alopecia in a pattern distribution. Archives of dermatology. 1994;130(6):770-4.

2. Aldoori N, Dobson K, Holden C, McDonagh A, Harries M, Messenger A.

Frontal fibrosing alopecia: possible association with leave-on facial skin care products and sunscreens; a questionnaire study. British Journal of Dermatology. 2016;175(4):762-7.

3. Donati A. Frontal fibrosing alopecia and sunscreens: cause or consequence? British Journal of Dermatology. 2016;175(4):675-6.

4. Kidambi AD, Dobson K, Holmes S, Carauna D, Del Marmol V, Vujovic A, et al. Frontal fibrosing alopecia in men: an association with leave-on facial cosmetics and sunscreens. British Journal of Dermatology. 2017;175:46-.

5. Cranwell WC, Sinclair R. Frontal fibrosing alopecia: Regrowth following cessation of sunscreen on the forehead. Australasian Journal of Dermatology. 2018. 6. Park ME, Zippin JH. Allergic contact dermatitis to cosmetics. Dermatologic clinics. 2014;32(1):1-11.

Table 1: history of sunscreen, moisturiser and cosmetic use in FFA and control subjects - frequencies and statistical analysis.

\begin{tabular}{|l|l|l|l|l|}
\hline \hline & FFA, $\mathbf{n}(\%)$ & $\begin{array}{l}\text { Controls, } \mathbf{n} \\
(\%)\end{array}$ & $\begin{array}{l}\text { Fisher's exact } \\
\text { test }\end{array}$ \\
\hline
\end{tabular}

This article is protected by copyright. All rights reserved 


\begin{tabular}{|c|c|c|c|}
\hline $\begin{array}{l}\text { "Do you regularly use the following } \\
\text { on the face or scalp?" }\end{array}$ & & & \\
\hline Sunscreen & $120(92)$ & $52(40)$ & $<0.0001$ \\
\hline Moisturiser & $81(62)$ & $72(55)$ & 0.3134 \\
\hline Cosmetics & $43(33)$ & $21(16)$ & 0.0023 \\
\hline \multicolumn{4}{|l|}{ Frequency of sunscreen use } \\
\hline I never use sunscreen & $9(7)$ & $50(38)$ & \\
\hline $\begin{array}{l}\text { I only use sunscreen when going out } \\
\text { into the sun }\end{array}$ & $1(1)$ & $\mid 28(22)$ & \\
\hline I use sunscreen daily in summer & $5(4)$ & $14(11)$ & \\
\hline I use sunscreen daily all-year & $115(88)$ & $38(29)$ & \\
\hline
\end{tabular}

This article is protected by copyright. All rights reserved 


\section{University Library}

\section{- M M N E R VA A gateway to Melbourne's research publications}

Minerva Access is the Institutional Repository of The University of Melbourne

Author/s:

Cranwell, WC; Sinclair, R

Title:

Sunscreen and facial skincare products in frontal fibrosing alopecia: a case-control study

Date:

2019-04-01

Citation:

Cranwell, W. C. \& Sinclair, R. (2019). Sunscreen and facial skincare products in frontal fibrosing alopecia: a case-control study. BRITISH JOURNAL OF DERMATOLOGY, 180 (4), pp.943-944. https://doi.org/10.1111/bjd.17354.

Persistent Link:

http://hdl.handle.net/11343/285252 